\title{
Colorectal Cancer Survival in Multiple Sclerosis
}

\section{A Matched Cohort Study}

Ruth Ann Marrie, MD, PhD, Colleen Maxwell, PhD, Alyson Mahar, PhD, Okechukwu Ekuma, MSc, Chad McClintock, MSc, Dallasl Seitz, MD, PhD, and Patti Groome, PhD

Neurology ${ }^{\circledR}$ 2021;97:e1447-e1456. doi:10.1212/WNL.0000000000012634

\author{
Correspondence \\ Dr. Marrie \\ rmarrie@hsc.mb.ca
}

\section{Abstract}

\section{Background and Objectives}

We tested the hypothesis that overall and cancer-specific survival after a colorectal cancer diagnosis is lower in persons with multiple sclerosis (MS) than in those without MS using a retrospective matched cohort design.

\section{Methods}

Using population-based administrative data in Manitoba and Ontario, we identified persons with MS from a validated case definition and linked these cohorts to cancer registries to identify those with colorectal cancer. We selected persons with colorectal cancer and without MS, matching 4:1 on birth year, sex, cancer diagnosis year, and region. We used Cox proportional hazards regression to compare all-cause survival between cohorts, adjusting for age at cancer diagnosis, cancer diagnosis year, income, region, and Elixhauser comorbidity score. We compared cancer-specific survival between cohorts using a cause-specific hazards model. We pooled findings across provinces using random-effects meta-analysis. Complementary analyses using a subcohort from Ontario, adjusted for cancer stage and disability status, as measured from the use of home care or long-term care services.

\section{Results}

We included 338 MS cases and 1,352 controls with colorectal cancer. The mean (SD) age at cancer diagnosis was 64.7 (11.1) years. After adjustment, MS was associated with an increased hazard for all-cause death that was highest 6 months after diagnosis (hazard ratio [HR] 1.45, 95\% confidence interval [CI] 1.19-1.76) and then declined over time ( $\mathrm{HR}$ [95\% CI] at 1 year 1.34 [1.09-1.63], 2 years $1.24[0.99-1.56], 5$ years 1.10 [0.80-1.50]). MS was associated with increased cancer-specific death at 6 months after diagnosis only (HR 1.29, 95\% CI 1.04-1.61). After adjustment for cancer stage, MS was associated with an increased hazard of death due to any cause $(1.60,95 \%$ CI 1.16-2.21) and with cancer-specific death (HR 1.47, 95\% CI 1.02-2.12). The association of MS and all-cause death was partially attenuated after adjustment for disability status (HR 1.37, 95\% CI 0.97-1.92), as was the association with cancer-specific death (HR 1.34, 95\% CI 0.91-1.97).

\section{Discussion}

Overall and cancer-specific survival was lower in persons with than without MS in the early period after colorectal cancer diagnosis. Further study is warranted to determine what factors underlie these worse outcomes. 


\section{Glossary}

$\mathbf{C I}=$ confidence interval; $\mathbf{H R}=$ hazard ratio; $\mathbf{I C D}=$ International Classification of Diseases; $\mathbf{M S}=$ multiple sclerosis; $\mathbf{O D B}=$ Ontario Drug Benefit; OHIP = Ontario Health Insurance Plan.

People living with multiple sclerosis (MS) have a lower life expectancy than individuals without MS. ${ }^{1,2}$ Cancer has been reported as the second or third most common cause of death in adults with MS, after MS. ${ }^{2-4}$ According to a systematic review, the 3 most common incident cancers in the MS population are cervical, breast, and colorectal cancers. ${ }^{5} \mathrm{Sim}$ ilarly, breast and colorectal cancers are 2 of the 4 cancers that account for half of cancer deaths in the adult general population. ${ }^{6}$ Recently, we found that women with MS had lower survival after breast cancer diagnosis than women without MS. ${ }^{7}$ This raises the question of whether MS is associated with lower survival after other common cancers.

Relatively little is known about the association between MS and survival after colorectal cancer diagnosis. ${ }^{8}$ In a Swedish study, survival after cancers of the upper and lower gastrointestinal tracts was higher in an MS cohort than in a non-MS cohort $^{8}$; this surprising finding contrasts with those reported for persons with other serious chronic illnesses such as diabetes and psychiatric disorders. ${ }^{9,10}$ Accurate prognostic information about cancer is critical to support therapeutic decision-making by persons with MS and their care providers.

Using a population-based matched cohort study, we compared overall survival and cancer-specific survival after colorectal cancer diagnosis in persons with MS and persons without MS. If survival were found to be lower in persons with MS, this would indicate that further investigation of the cancer care trajectory such as participating in screening, time to diagnosis, and cancer treatment and the role of MS-specific factors would be warranted.

\section{Methods}

\section{Setting and Design}

Forty-two percent of the Canadian population resides in the provinces of Manitoba and Ontario. We included these 2 provinces because of the combined population size of $\approx 14$ million people, as well as their differing sizes (Manitoba's population is 1.4 million) and organization of health services, to improve generalizability of our findings. Each province is responsible for delivery of universal, publicly funded medically necessary services. As part of health systems management, these provinces prospectively record the use of health care services by nearly all residents in administrative databases. Because privacy regulations do not permit person-level data to leave the province of origin, we applied the same protocol in each province.

In both provinces, the databases used included the respective provincial population registries: the Discharge Abstract Database, medical/physician services (in Ontario, the Ontario
Health Insurance Plan [OHIP]), and the Cancer Registry. In Manitoba, we accessed the administrative databases through the Manitoba Population Research Data Repository at the Manitoba Centre for Health Policy (MCHP). These databases were linked with the use of an encrypted unique provincial identifier. In Ontario, we accessed administrative databases at ICES. ICES is an independent, nonprofit research institute with a legal status under Ontario's health information privacy law that allows it to collect and analyze health care and demographic data, without consent, for health system evaluation and improvement. These databases were linked through the use of unique encoded identifiers and analyzed at ICES. The population registries provided sex, region of residence (postal code), dates of birth, dates of death, and dates of health care coverage. The Discharge Abstract Database captures hospital admission and separation dates and discharge diagnoses. These diagnoses are recorded using the ICD system, either ICD-9-Clinical Modification or ICD-10-Canada, depending on the year. Medical/physician services (OHIP) capture the date of service and physicianassigned diagnoses using 3-digit ICD-9 codes. In Ontario only, we accessed the Ontario Drug Benefit (ODB) database, which captures prescription drug dispensations for all those $\geq 65$ years of age and receiving home care or long-term care (i.e., nursing home). Use of the ODB allowed us to identify persons residing in long-term care settings. In Ontario, we also accessed the Home Care Database, which captures individuals who have received home care services since 2005 . Since 1965, the Manitoba Cancer Registry has captured cancer cases in Manitoba, with a completeness of $95 \%$ to 98\%. ${ }^{11}$ Cancer stage has been captured since 2004. Completeness of the Ontario Cancer Registry is $98 \%$, and cancer cases have been recorded since $1964 .{ }^{12}$ Cancer stage data have been captured since 2007. We linked postal code to area-level census data from Statistics Canada to determine the average household income of each individual's enumeration area. ${ }^{13}$

\section{Standard Protocol, Approvals, Registrations, and Patient Consents}

The University of Manitoba Health Research Ethics Board and Queen's Research Ethics Boards approved the study. The Manitoba Health Information Privacy Committee approved data access. Administrative data access (via ICES) was authorized under section 45 of Ontario's Personal Health Information Protection Act.

\section{Study Populations}

The study period was January 1, 1994, to December 31, 2016. We applied a validated case definition that identified persons with MS as those who ever had $\geq 3$ hospital or physician claims for MS based on ICD-9 or ICD-10-Canada diagnostic codes 
(340/G35). ${ }^{14}$ For each person who met the MS case definition, we sought the earliest ICD-9 or ICD-10 claim for CNS demyelinating disease to determine the MS diagnosis date. This prevalent MS cohort was linked to the cancer registries. We then identified members of the MS cohort with incident colorectal cancer after MS diagnosis using ICD-O-3 topography codes (C18.0, C18.2-C18.9, C19.9, C20.9, C26.0). We designated the date of colorectal cancer diagnosis as the study index date. Next, we excluded anyone who (1) did not have a valid provincial registration number; (2) was not resident in the province with provincial health insurance for $\geq 12$ months before the index date (eligibility is lost due to death or emigration); (3) was $<18$ years of age at the index date; (4) had any cancer before the index date; (5) had concurrent cancer, defined as subsequent cancer diagnosed within 6 months after the index date; or (6) had carcinoma in situ at diagnosis (Figure 1). This constituted the MS-colorectal cancer cohort. To identify a matched cohort, we selected all persons diagnosed with colorectal cancer without MS. We excluded anyone with diagnostic codes for any CNS demyelinating disease, including MS, and then applied the same exclusion criteria as for the MS cohort. From this pool of potential matches, we chose 4 persons matched on sex, year of birth \pm 3 years, year of colorectal cancer diagnosis \pm 2 years, and region of residence (first 2 digits of postal code) at the index date. Cases with $<4$ matches were excluded.

\section{Outcomes}

The primary outcome was overall survival (considering all causes of death, including MS) after colorectal cancer diagnosis, truncated at 5 years, reflecting that this is the typical benchmark in colorectal cancer. ${ }^{15}$ The secondary outcome was cancer-specific survival, defined as any cancer death and also truncated at 5 years. We also describe cancer stage at diagnosis to characterize the cohorts. The stage of cancers that originate from solid tumors is described with the Union for International Cancer Control TNM classification of malignant tumors, which considers the size of the primary tumor, whether it has invaded local tissue, regional lymph node involvement, and presence of metastases. This information can

Figure 1 Directed Acyclic Graph of the Association Between MS and Death After Colorectal Cancer Diagnosis

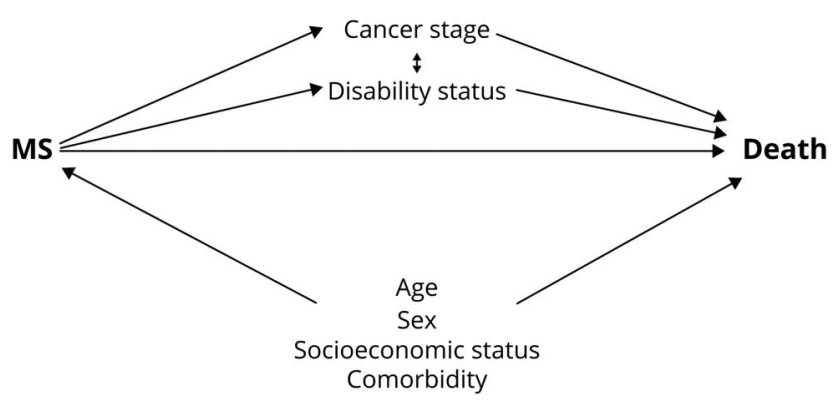

MS = multiple sclerosis. be combined into an overall stage grouping that ranges from 0 (in situ) to IV, or unknown, for each cancer. ${ }^{16}$ Cancer stage was grouped as I/II and III/IV to allow consistent reporting across provinces while meeting privacy requirements not to report cell sizes $<6$.

\section{Covariates}

We included several covariates that are associated with cancer survival, including age at cancer diagnosis (continuous), region of residence (urban [reference group] vs rural), socioeconomic status, cancer diagnosis year (1994-2004 [reference group], 2005-2009, 2010-2016), and comorbidity. ${ }^{10}$ In Ontario, we classified urban regions as communities with populations $\geq 100,000$ based on the census metropolitan areas or census agglomeration. In Manitoba, we classified the only 2 cities (populations of 47,000 and 600,000 ) as urban. We categorized socioeconomic status, based on quintiles of average household income, as lowest quintile, quintiles 2 to 4 , and highest quintile (reference). We included cancer diagnosis year to account for temporal trends in colorectal cancer incidence and survival. ${ }^{17}$ We used the Elixhauser comorbidity index (continuous variable) with a 1-year lookback period because it adjusts better for comorbidity in cancer studies than other indices. ${ }^{18}$ The index was modified to exclude cancer diagnosis codes so that we would not misclassify metastases or secondary cancers as comorbidity. Similarly, we excluded paralysis and demyelinating disease codes to avoid misclassifying MS-related symptoms as comorbidity. Notably, the index captures obesity and drug and alcohol abuse in addition to chronic health conditions. We updated socioeconomic status, region (urban/rural), and comorbidity status at the study midpoint to account for changes in status and to address nonproportionality identified during testing of Cox regression model assumptions. In Ontario, we also measured disability status (as of 2007) based on receipt of home care services or admission to a long-term care facility. Home care services are provided only to individuals with persistent impairments in functional status. Nearly half of individuals with MS who receive home care in Canada use a wheelchair and have some degree of cognitive impairment; one-third report falling; and one-third are incontinent. When health care needs are too great to be met in the community, long-term care (i.e., nursing home) is provided. In Canada, 8 of 10 persons with MS residing in long-term care require a wheelchair and have some degree of cognitive impairment, making long-term care admission a highly specific marker of severe disability. ${ }^{19}$ We used $\geq 1$ OHIP fee code for services delivered in long-term care or the long-term care code in the ODB to identify long-term care admissions ${ }^{20,21}$; this definition has a positive predictive value of 93.2\% and negative predictive value of $99.9 \%{ }^{22}$ The earliest long-term care code identified constituted the date of disability in that setting. Thus, use of either home care or long-term care indicated the presence of moderate to severe disability.

\section{Analysis}

We characterized the cohorts using descriptive statistics including frequency (percent), mean (SD), and median 
(interquartile range). The cohorts were compared by the use of standardized differences (values of 0.20-0.49 represent small effect sizes, values of $0.50-0.79$ represent medium effect sizes, and values $\geq 0.80$ represent large differences between cohorts in baseline characteristics). ${ }^{23}$ We reported crude case fatality rates (deaths per 100 person-years) in the 2 cohorts.

We used Cox proportional hazards models to examine the association between MS and all-cause survival after colorectal cancer diagnosis in which zero time was the colorectal cancer diagnosis date. Each participant was followed up until emigration/loss of provincial health care eligibility, death due to any cause, or the end of the study period (December 31, 2016), whichever came first. Because follow-up varied between the MS and matched cohorts due to differential survival, the matching factors were included as covariates, ${ }^{24}$ along with the other covariates described above. In colorectal cancer, comorbid diseases such as MS may influence the stage of illness at diagnosis, and cancer stage is associated with survival. $^{25}$ In addition, a study in British Columbia, Canada, found that compared to persons without MS, persons with MS had larger tumors at diagnosis with colorectal, breast, lung, or prostate cancers. ${ }^{26}$ Therefore, we did not adjust for cancer stage in the primary model because we considered it a causal intermediate, that is, a mediator of the association between MS and survival (Figure 1). We tested the proportional hazard assumption using graphical methods and timedependent covariates. ${ }^{27}$ This assumption was not met for the MS vs non-MS variable; the violation of the assumption was more pronounced in Manitoba than in Ontario. Therefore, we included an interaction term between MS and the natural log of time, and we report hazard ratios at 6 months and 1,2 , and 5 years after diagnosis.

To test the association between MS and cancer-specific survival, we used a cause-specific hazard model that accounted for the competing risk of death to other (noncancer) causes ${ }^{28}$ and adjusted for the same covariates as for the all-cause survival model. In each regression model, we tested for interactions between cohort (MS vs controls) and age and cancer diagnosis year. We used random-effects meta-analysis to pool adjusted hazard ratios (HRs) and 95\% confidence intervals [CIs] from the regression models. ${ }^{29}$ We reported $I^{2}$ as a measure of heterogeneity of the findings between provinces, ${ }^{30}$ where $I^{2} \leq 25 \%$ indicates low heterogeneity and $I^{2} \geq 75 \%$ indicates high heterogeneity.

\section{Complementary Analysis}

We conducted several complementary analyses. First, for our primary model, we calculated the E-value to determine the sensitivity of our findings to unmeasured confounders, where the E-value is a function of the strength of association (HR) of the exposure (i.e., MS) and the outcome (i.e., death). It describes the strength of association needed between an unmeasured confounder and both the exposure and the outcome to explain away the observed association of interest. $^{31,32}$ Second, among individuals in Ontario diagnosed in 2007 or later for whom cancer stage data were available, we incorporated stage (in 4 separate groups) as a covariate, viewing stage as a potential mediator of the association between MS and survival (Figure 1). Notably, the proportional hazards assumption for the MS vs non-MS variable was not violated for the subcohort, but there was an interaction between stage and age. This analysis was not possible in Manitoba due to the small size of the cohorts. Third, we explored the association between disability status and survival in Ontario, where the study population was large enough, to understand how much of the potential survival differences was mediated by differences in underlying disability between those with MS and those without (Figure 1). We expected that including this covariate would attenuate the association between MS and survival.

Statistical analyses were performed with SAS version 9.4 (SAS Institute Inc, Cary, NC).

\section{Data Availability}

The source data for Manitoba are not owned by the researchers or MCHP and thus cannot be provided to a public repository. With the appropriate approvals, the Manitoba data can be accessed through the MCHP. The Ontario dataset from this study is held securely in coded form at ICES. While data-sharing agreements prohibit ICES from making the dataset publicly available, access may be granted to those who meet prespecified criteria for confidential access.

\section{Results}

\section{Study Populations}

After we applied the inclusion and exclusion criteria, we identified 338 MS cases and 1,352 non-MS controls with colorectal cancer (Figure 2). As expected, the MS and nonMS cohorts were similar with respect to the matching factors of sex, age (year of birth), year of cancer diagnosis, and region (Table 1). The peak age group at diagnosis of colorectal cancer was $\geq 70$ years, followed by 60 to 69 years. More than

Figure 2 Flowchart of Participant Selection for Analysis

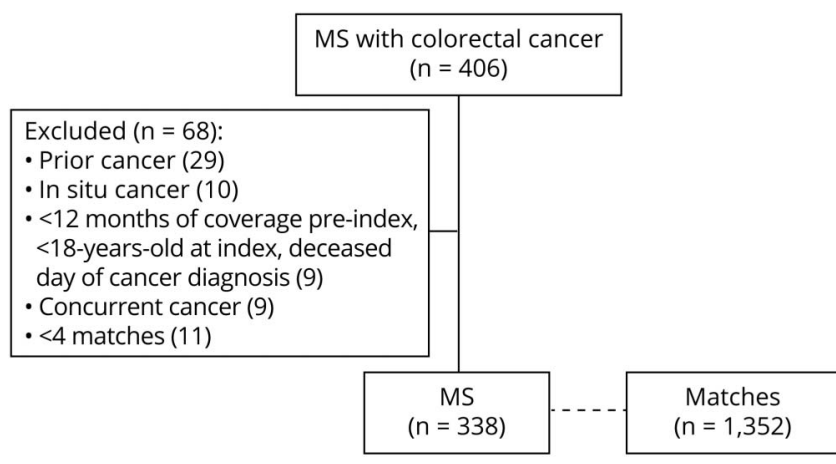

MS = multiple sclerosis. 
Table 1 Demographic Characteristics of MS and Matched Colorectal Cancer Populations

\begin{tabular}{|c|c|c|c|c|c|c|c|}
\hline \multirow[b]{2}{*}{ Variable value } & \multicolumn{2}{|l|}{ Ontario } & \multicolumn{2}{|l|}{ Manitoba } & \multicolumn{2}{|l|}{ Combined } & \multirow[b]{2}{*}{ Std diff } \\
\hline & MS & Matched controls & MS & Matched controls & MS & Matched controls & \\
\hline No. & 307 & 1,228 & 31 & 124 & 338 & 1,352 & \\
\hline Age at index date, mean (SD), y & $64.4(11.2)$ & $64.5(11.1)$ & $66.6(10.4)$ & $66.5(10.2)$ & $64.6(11.1)$ & $64.7(11.1)$ & 0.01 \\
\hline \multicolumn{8}{|l|}{ Age at index date category, $\mathrm{n}(\%)$} \\
\hline $18-49 y$ & $27(8.8)$ & s & s & s & $27(8.0)$ & $102(7.5)$ & 0.02 \\
\hline $50-59$ y & $86(28.0)$ & s & s & s & $96(28.4)$ & $385(28.5)$ & 0 \\
\hline $60-69 y$ & $91(29.6)$ & $372(30.3)$ & $7(22.6)$ & $34(27.4)$ & $98(30.0)$ & $406(30.0)$ & 0 \\
\hline$\geq 70 y$ & $103(33.6)$ & $406(33.1)$ & $14(45.2)$ & $53(42.7)$ & $117(34.6)$ & 459 (33.9) & 0.01 \\
\hline Female sex, n (\%) & $196(63.8)$ & $784(63.8)$ & $18(58.1)$ & $72(58.1)$ & $214(63.3)$ & $856(63.3)$ & 0 \\
\hline \multicolumn{8}{|l|}{ Cancer diagnosis year, $\mathbf{n}(\%)$} \\
\hline 1994-2004 & $92(30.0)$ & $363(29.6)$ & $15(48.4)$ & $62(50.0)$ & $107(31.6)$ & $425(31.4)$ & 0 \\
\hline 2005-2009 & $74(24.1)$ & $311(25.3)$ & $7(22.6)$ & $25(20.2)$ & $81(24.0)$ & $336(24.8)$ & 0.02 \\
\hline$\geq 2010$ & $141(45.9)$ & $554(45.1)$ & $9(29.0)$ & $37(29.8)$ & $150(44.4)$ & $591(43.7)$ & 0.01 \\
\hline \multicolumn{8}{|l|}{ Income quintile at index, $\mathrm{n}(\%)$} \\
\hline Quintile 1 & $58(18.9)$ & $235(19.1)$ & $6(19.4)$ & $23(18.6)$ & 64 (18.9) & $258(19.1)$ & 0 \\
\hline Quintiles 2-4 & $190(61.9)$ & $745(60.7)$ & $14(45.2)$ & $78(62.9)$ & $204(60.4)$ & $823(60.9)$ & 0.01 \\
\hline Quintile 5 & $59(19.2)$ & $244(19.9)$ & $9(29.0)$ & $20(16.1)$ & $68(20.1)$ & $264(19.5)$ & 0.02 \\
\hline $\begin{array}{l}\text { Urban region of residence at } \\
\text { index, }{ }^{a} \mathbf{n}(\%)\end{array}$ & $261(85.0)$ & $1,047(85.3)$ & $21(67.7)$ & $79(63.7)$ & $282(83.4)$ & $1,126(83.3)$ & 0.01 \\
\hline \multicolumn{8}{|l|}{ Elixhauser score, n (\%) } \\
\hline $0-1$ & $173(56.4)$ & $719(58.6)$ & $18(58.1)$ & $76(61.3)$ & $191(56.5)$ & 795 (58.8) & 0.04 \\
\hline$>1$ & 134 (43.6) & $509(41.4)$ & 13 (41.9) & $48(38.7)$ & 147 (43.5) & $557(41.2)$ & 0.04 \\
\hline $\begin{array}{l}\text { Time to death, loss to follow-up, } \\
\text { or study end, mean (SD), y }\end{array}$ & $2.67(1.95)$ & 3.05 (1.89) & $2.60(2.11)$ & $2.99(1.96)$ & $2.66(1.96)$ & $3.04(1.90)$ & 0.20 \\
\hline
\end{tabular}

Abbreviations: MS = multiple sclerosis; $\mathrm{s}=$ cell sizes $\leq 5$ suppressed to protect privacy; Std Diff = standardized difference.

${ }^{\text {a }}$ Missing for $\leq 5$ controls in Ontario at index.

$40 \%$ of individuals were diagnosed in 2010 or later, and most lived in urban settings. In the MS and matched cohorts combined, individuals (reported from 2004 onward in Manitoba and 2007 onward in Ontario: 436 of 1,246 [35.0\%]) were diagnosed with stage I or II colorectal cancer. This did not differ between cohorts (stage I/II cancer: MS 93 of 201 [46.2\%], controls 343 of 810 [42.3\%]; stage III/IV cancer: MS 92 of 201 [45.8\%], controls 417 of 810 [51.5\%], $p=0.30)$.

\section{Survival}

The 5-year case fatality rate was $41 \%$ higher in the MS cohort than in the matched cohort (Figure 3 and Table 2). As expected, cancer-specific case fatality rates were lower in both cohorts, but the cancer-specific fatality rate was $27 \%$ higher in the MS cohort than in the matched cohort (Figure 4 and Table 2). Overall, of the 150 members of the MS cohort who died of any cause, 115 (76.7\%) were due to cancer, and 18 (12.0\%) were secondary to MS as the underlying cause.
After adjustment for age at cancer diagnosis, cancer diagnosis year, income quintile, region, and Elixhauser comorbidity score, MS was associated with an increased hazard for death that was greatest at 6 months after the cancer diagnosis and then diminished such that it was no longer statistically significant by 2 years after diagnosis (Table 3 ) in the context of a smaller population at risk. MS was also associated with an increased hazard of cancer-specific death, but only at 6 months after diagnosis (Table 3). We did not observe any statistical interactions between cohort and either age at the index date or year of diagnosis.

In Ontario, cancer stage data were available from 2007 onward; this subcohort included 162 individuals with MS and 664 individuals without MS. Within this subcohort, 49 (30.2\%) individuals with MS and 69 (10.4\%) without MS were disabled. Individuals with MS were also less likely to have stage IV cancer at diagnosis (13\%) than individuals 


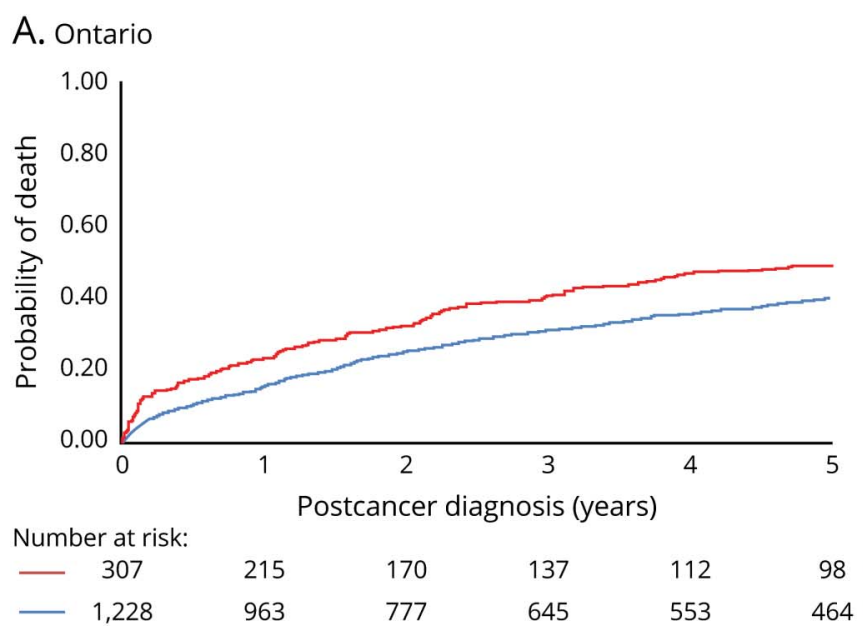

B. Manitoba

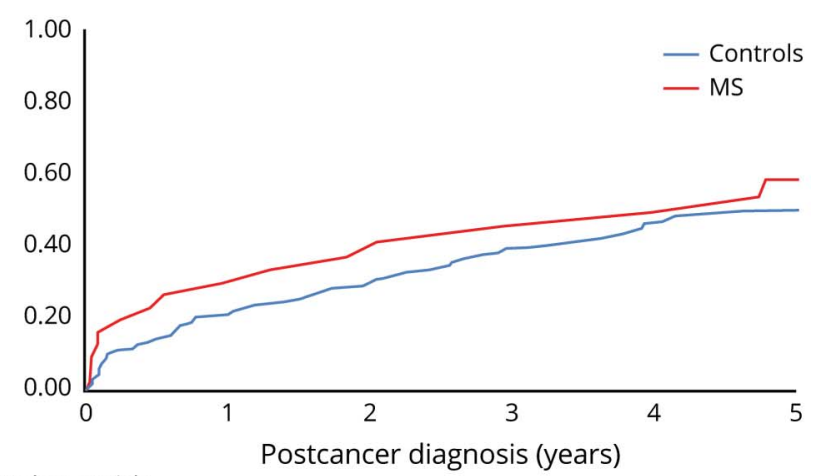

Number at risk:

$\begin{array}{ccccccc}9 & \text { Number at risk: } & & & & \\ 98 & -31 & 21 & \mathrm{~s} & 15 & \mathrm{~s} & 10 \\ 464- & 124 & 92 & 76 & 66 & 54 & 31\end{array}$

(A) Ontario and (B) Manitoba. MS = multiple sclerosis; s = suppressed to protect privacy and confidentiality.

without MS (19.7\%, standardized difference 0.18). When we repeated the main analysis in the Ontario cohort on members diagnosed in 2007 or later, the associations between MS and death due to any cause (HR 1.22, 95\% CI 0.89-1.68) and due to cancer (HR 1.09, 95\% CI 0.76-1.56) were not statistically significant. After adjustment for cancer stage, MS was associated with an increased hazard of death due to any cause (1.60; 95\% CI 1.16-2.21) and with cancer-specific death (HR $1.47,95 \%$ CI 1.02-2.12). The association of MS and all-cause death was partially attenuated after adjustment for disability status (HR 1.37, 95\% CI 0.97-1.92), as was the association with cancer-specific death (HR 1.34, 95\% CI 0.91-1.97).

\section{Discussion}

In this population-based retrospective study, we compared survival after colorectal cancer diagnosis in cohorts with and without MS. In our main analysis, we found that all-cause survival was lower in the MS cohort in the first 6 to 12 months after diagnosis and that cancer-specific survival was lower in the first 6 months after diagnosis. On the basis of $I^{2}$, there was no heterogeneity in the estimates between the 2 provinces. Our analyses testing the sensitivity of our findings to unmeasured confounders suggest that only factors associated with MS and survival with a strength of association exceeding 5.8 could account for our findings. In our analyses of the Ontario subcohort of members diagnosed in 2007 or later, MS was associated with lower all-cause and cancer-specific survival after accounting for cancer stage. Among those with MS who died, three-quarters of deaths were due to cancer and 1 in 8 deaths was due to MS as the underlying cause. This is a shift from the usual distribution in the MS population as a whole; in Manitoba, $54.1 \%$ of deaths were attributed to MS during the period of 2000 to 2011 . $^{2}$

To the best of our knowledge, only 1 other study has examined survival after gastrointestinal cancer in persons with MS. Over the period of 1969 to 2005, 280 persons with MS in Sweden had better survival after any gastrointestinal cancer than 4,820 persons without MS after adjusting for age, sex, region, and socioeconomic status. ${ }^{8}$ Survival specifically after colorectal cancer diagnosis was not reported. Cancer-specific survival also was not reported. Consistent with our findings,

Table 2 Five-Year All-Cause and Cancer-Specific Case Fatality Rates (95\% Cls) per 100 Person-Years in MS Cases and Matched Controls

\begin{tabular}{|c|c|c|c|c|c|}
\hline \multirow[b]{2}{*}{ Mortality } & \multicolumn{2}{|l|}{ Ontario } & \multicolumn{2}{|l|}{ Manitoba } & \multirow[b]{2}{*}{ Pooled RR $(95 \% \mathrm{CI})$} \\
\hline & MS & Matched controls & MS & Matched controls & \\
\hline Person-years & 818.6 & $3,749.9$ & 80.7 & 370.6 & \\
\hline Overall & $16.4(13.8-19.4)$ & $11.5(10.5-12.6)$ & $19.8(12.2-32.4)$ & $15.4(11.9-19.9)$ & $1.41^{a}(1.17-1.69)$ \\
\hline Cancer-specific & $12.7(10.5-15.4)$ & $9.9(8.9-11.0)$ & $13.6(7.55-24.6)$ & $13.0(9.76-17.2)$ & $1.27^{\mathrm{b}}(1.03-1.56)$ \\
\hline
\end{tabular}

Abbreviations: $\mathrm{Cl}=$ confidence interval; $\mathrm{MS}=$ multiple sclerosis; $\mathrm{RR}=$ rate ratio.

${ }^{\text {a }} p=0.0002, I^{2}=0 \%(p=0.74)$.

${ }^{\mathrm{b}} p=0.03, I^{2}=0 \%(p=0.67)$. 

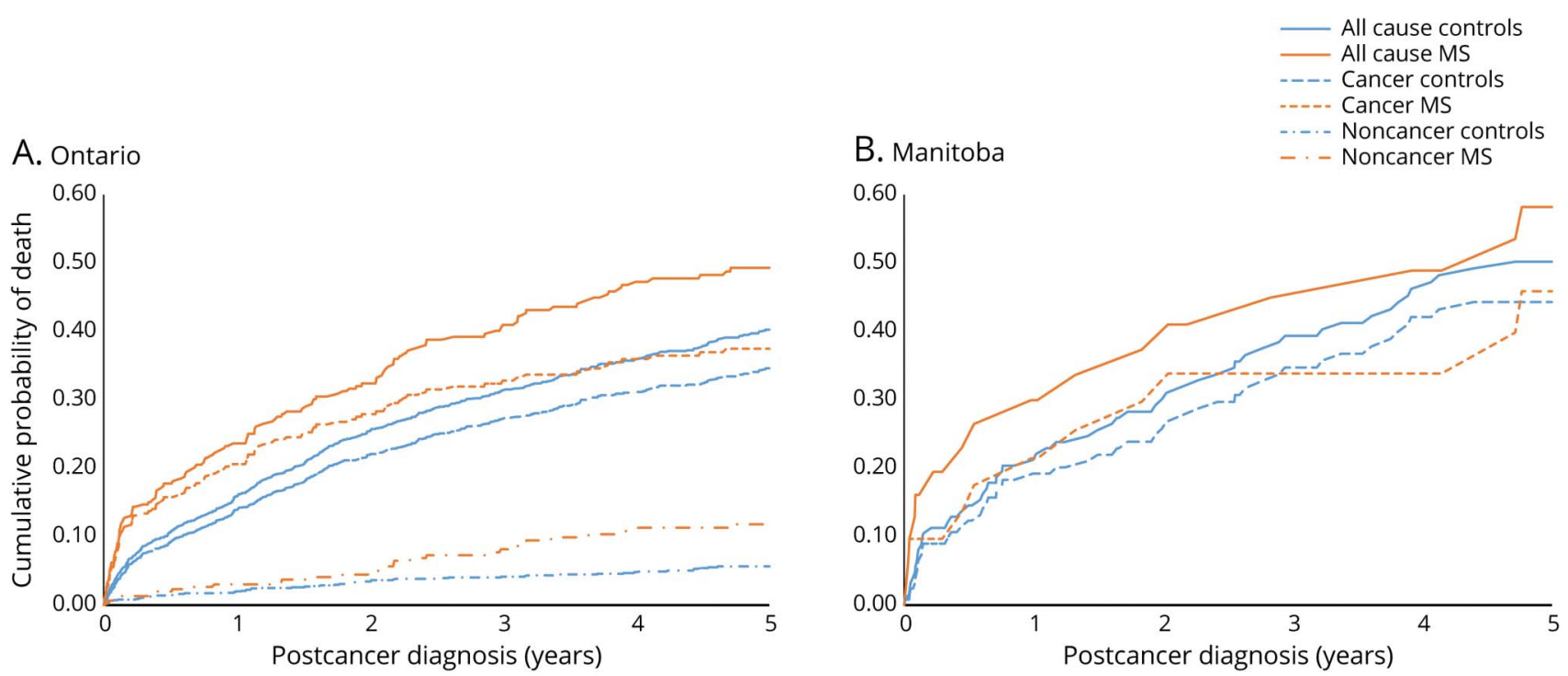

(A) Ontario and (B) Manitoba (noncancer deaths suppressed due to small cell sizes). MS = multiple sclerosis.

other serious comorbid chronic conditions are associated with lower survival after colorectal cancer diagnosis. In a 2018 systematic review of 35 studies, patients with colorectal cancer with comorbid conditions had an increased risk of 30-day (HR 1.71, 95\% CI 1.26-2.31), overall (HR 1.41, 95\% CI 1.23-1.62), and cancer-specific (HR 1.06, 95\% CI 1.02-1.10) death. ${ }^{10}$

We considered cancer stage to be a potential mediator of survival on the basis of the literature in MS and other comorbid diseases, that is, that MS might influence cancer stage at diagnosis. In the Ontario subcohort, people with MS were slightly less likely to have stage IV cancer at diagnosis, so when we accounted for cancer stage, the association between MS and death was strengthened. The adverse effects of comorbidity on survival in colorectal cancer appear to differ according to cancer stage. ${ }^{25}$ For example, in a sample of 35,755 adults $\geq 67$ years of age diagnosed with colorectal cancer, comorbidity was associated with reduced survival; the effect was greatest in early-stage cancer. ${ }^{33}$ Efforts have been made to generate better estimates of survival according to age

Table 3 Adjusted $^{\mathrm{a}}$ HRs (95\% Cls) for the Association Between MS and Mortality After Colorectal Cancer

\begin{tabular}{|c|c|c|c|c|c|}
\hline Survival (MS vs matched cohort) & Ontario & Manitoba & Pooled estimate $^{b}$ & $I^{2}$ value & E-value \\
\hline \multicolumn{6}{|l|}{ Overall } \\
\hline $6 \mathrm{mo}$ & $1.45(1.19-1.76)$ & $1.48(0.41-5.30)$ & $1.45(1.19-1.76)^{d}$ & 0 & $8.53(3.31-27.8)$ \\
\hline $1 y$ & $1.33(1.08-1.63)$ & $1.45(0.68-3.08)$ & $1.34(1.09-1.63)^{\mathrm{e}}$ & 0 & $5.80(2.12-16.3)$ \\
\hline $2 y$ & $1.21(0.95-1.55)$ & $1.42(0.78-2.60)$ & $1.24(0.99-1.56)$ & 0 & $4.03(1.00-12.6)$ \\
\hline $5 y$ & $1.08(0.78-1.49)$ & $1.39(0.42-4.55)$ & $1.10(0.80-1.50)$ & 0 & \\
\hline \multicolumn{6}{|l|}{ Cancer-specific $^{c}$} \\
\hline $6 \mathrm{mo}$ & $1.30(1.04-1.62)$ & $1.09(0.28-4.17)$ & $1.29(1.04-1.61)^{f}$ & 0 & $4.85(1.59-15.1)$ \\
\hline $1 y$ & $1.11(0.88-1.42)$ & $1.05(0.49-2.24)$ & $1.11(0.88-1.40)$ & 0 & \\
\hline $2 y$ & $0.96(0.72-1.28)$ & $1.01(0.55-1.83)$ & $0.97(0.75-1.26)$ & 0 & \\
\hline $5 y$ & $0.78(0.54-1.15)$ & $0.96(0.27-3.38)$ & $0.80(0.56-1.15)$ & 0 & \\
\hline
\end{tabular}

Abbreviations: $\mathrm{Cl}=$ confidence interval; $\mathrm{HR}=$ hazard ratio; $\mathrm{MS}=$ multiple sclerosis.

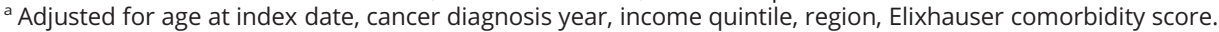

b Pooled using random effects meta-analysis.

'Cause-specific hazard model.

d $p=0.0002$

e $p=0.004$.

f $p=0.02$. 
and sex by incorporating comorbidity scores, ${ }^{34}$ but MS was not included among the comorbid conditions considered.

In our primary analysis, survival was lower in the MS cohort particularly in the first 6 to 12 months. In our complementary analyses, we did not observe this time-dependent effect, and survival in the MS cohort was lower throughout the entire 5year postcancer follow-up period. In Canada and other countries, population-based cancer registry data show that colorectal cancer survival generally has improved over time, particularly in the first year after diagnosis ${ }^{15}$; however, improvements in survival have differed across groups. In Ontario between 1993 and 2009, colorectal cancer-specific survival improved more for people in the highest income quintile than in the lowest income quintile. ${ }^{35}$ The reasons for lower survival in the MS cohort are uncertain. These may include undertreatment of the cancer or reduced resilience to cope with the effects of cancer and treatment toxicity. After diagnosis, the primary treatment of colorectal cancer involves surgery to remove the tumor. In individuals $<75$ years of age, higher comorbidity burden is associated with a lower likelihood of receiving curative cancer resection. ${ }^{36,37}$ Comorbidity is also associated with a lower likelihood of receiving adjuvant chemotherapy at all ages. The surgery and associated complications may be more difficult for persons with MS to tolerate than for persons without MS due to existing morbidity. In a prior Canadian study of 2,104 persons with MS, those who were hospitalized accrued substantially increased MS-related disability after their hospitalizations. ${ }^{38}$ Individuals with MS are also more likely to die after serious health events such as acute myocardial infarctions and after intensive care unit $\operatorname{admission}^{39,40}$; the risk of death is higher at 30 days after these events than at 365 days. Individuals with higher burdens of comorbid disease or polypharmacy may not be good candidates for adjuvant chemotherapy. Predictors of death resulting from colorectal cancer within 6 months of diagnosis include metastatic disease (captured in cancer stage), age, and performance status. This is consistent with observations that frailty in older patients with cancer is associated with increased postoperative mortality, postoperative complications, and intolerance to cancer treatment. ${ }^{41}$ In persons with MS, disability is strongly associated with frailty. ${ }^{42}$ Our disability measure aimed to capture individuals with poor performance status according to their use of home care and long-term care services; most individuals in such Canadian settings are frail. Although our exploratory analyses including disability as a covariate should be viewed cautiously due to the modest number of individuals affected and the focus on more severe forms of disability, they raise the possibility that disability mediates some of the association between MS and reduced survival in colorectal cancer. Future studies should capture a broader range of disability status and disability measures and examine whether they are associated with undertreatment or early adverse outcomes such as postoperative complications and mortality or intolerance to chemotherapy. A better understanding of colorectal cancer pathways, including diagnostic delays, adequacy of diagnostic processes and staging, treatment decisions, treatment intervals, intensity of treatment, multispecialty coordination of care, and adequacy of follow-up testing and detection of cancer recurrence, ${ }^{43,44}$ and outcomes could be helpful for clinicians counseling persons with MS as they attempt to balance the benefits of cancer treatment with the potential adverse effects and toxicity in the context of life expectancy, quality of life, and their existing health status. Another area that warrants investigation is how accommodating the cancer care system is for people with disabilities and how the system could be modified to better serve these individuals.

This study had several strengths, including the populationbased design executed in 2 provinces. We identified the MS cohort using a validated case definition and identified colorectal cancers using high-quality registries. Unlike the limited prior studies of cancer survival in MS, we assessed all-cause and cancer-specific survival. Our regression models accounted for temporal trends in cancer diagnosis, sociodemographic factors, and comorbidity. This study also had limitations. We used a comorbidity index that performs well in cancer studies; however, we may not have accounted for all relevant comorbid conditions. ${ }^{18}$ We used a broad definition of cancer death rather than death due specifically to colorectal cancer because physicians tend to report a nonspecific site on death certificates rather than the specific (primary) site, potentially leading to underestimates of cancer-specific deaths. $^{45-47}$ The administrative data we used lacked information regarding race, ethnicity, and health behaviors, factors that may influence colorectal cancer survival. ${ }^{48,49}$ However, we accounted for the most important prognostic factors, including cancer stage and age. ${ }^{48,49}$ Other prognostic factors such as molecular features of the cancer were not captured, but there is no known reason why these would differ between people with and those without MS. ${ }^{50}$ In addition, our E-value analysis suggested that any such factors would be unlikely to fully account for our findings given that the known effects of these factors are modest. We could not assess how exposure to disease-modifying therapy may influence cancer survival within the MS cohort because Ontario lacks population-based prescription data for persons $<65$ years of age and the number of cancer cases in Manitoba was relatively small. Future studies should investigate the mechanisms by which cancer survival is lower in persons with MS by considering the entire care cancer pathway.

We found that early survival was lower in persons with MS than without MS after the diagnosis of colorectal cancer. This has potential implications for clinical decision-making, and further study is warranted to determine what factors underlie these worse outcomes.

\section{Acknowledgment}

The authors acknowledge the MCHP for use of the Population Health Research Data Repository under project No. 2014-030 (HIPC No. 2019/2020-02). The results, inferences, opinions, and conclusions presented are those of the authors and no official endorsement by the MCHP, 
Manitoba Health, the Vital Statistics Agency, the Data Stewards, or other data providers is intended or should be inferred. This study was supported by ICES, which is funded by an annual grant from the Ontario Ministry of Health and Ministry of Long-Term Care. Parts of this material are based on data and information compiled and provided by the Ministry of Health and Ministry of Long-Term Care, Canadian Institute for Health Information, and Cancer Care Ontario. The analyses, conclusions, opinions and statements expressed herein are solely those of the authors and do not reflect those of the funding or data sources; no endorsement is intended or should be inferred. The authors thank IQVIA Solutions Canada Inc for use of their Drug Information File. Parts of this report are based on Ontario Registrar General information on deaths, the original source of which is ServiceOntario. The views expressed herein are those of the authors and do not necessarily reflect those of Ontario Registrar General or the Ministry of Government Services.

\section{Study Funding}

This study was funded by the MS Society of Canada (EGID 3463). R.A.M. is supported by the Waugh Family Chair in Multiple Sclerosis and a Manitoba Research Chair from Research Manitoba.

\section{Disclosure}

R.A. Marrie receives research funding from the Canadian Institutes of Health Research (CIHR), Research Manitoba, Multiple Sclerosis Society of Canada, Multiple Sclerosis Scientific Foundation, Crohn's and Colitis Canada, National Multiple Sclerosis Society, Consortium of Multiple Sclerosis Centers, the US Department of Defense, Roche, Biogen, and the government of Alberta. She is supported by the Waugh Family Chair in Multiple Sclerosis. C. Maxwell is supported by a University Research Chair (University of Waterloo) and receives funding from CIHR, Canadian Frailty Network, Multiple Sclerosis Society of Canada, CMSC, Ontario Neurodegenerative Disease Research Initiative Phase 2, Velux Stiftung, Queen's University, and PSI. Foundation. A. Mahar receives research funding from CIHR, MS Society of Canada, Ontario Institute for Cancer Research, Social Sciences and Humanities Research Council, Children's Hospital Research Institute of Manitoba, Veteran's Affairs Canada, Sherif Hanna Surgical Oncology Research Fund at Sunnybrook Health Sciences Centre, Terry Fox Research Institute, Canada Foundation for Innovation, Research Manitoba, the True Patriot Love Foundation, and the University of Manitoba. O. Ekuma and C. McClintock report no disclosures relevant to the manuscript. D. Seitz receives research funding from CIHR, the MS Society of Canada, and the University of Calgary and is the site investigator for a clinical trial sponsored by Hoffman La Roche. P. Groome receives research funding from the Multiple Sclerosis Society of Canada. Go to Neurology.org/ $\mathrm{N}$ for full disclosures.

\section{Publication History}

Received by Neurology April 13, 2021. Accepted in final form July 16, 2021.
Appendix Authors

\begin{tabular}{|c|c|c|}
\hline Name & Location & Contribution \\
\hline $\begin{array}{l}\text { Ruth Ann } \\
\text { Marrie, MD, } \\
\text { PhD }\end{array}$ & $\begin{array}{l}\text { Departments of Internal } \\
\text { Medicine and Community } \\
\text { Health Sciences, Max Rady } \\
\text { College of Medicine, Rady } \\
\text { Faculty of Health Sciences, } \\
\text { University of Manitoba, } \\
\text { Winnipeg, Canada }\end{array}$ & $\begin{array}{l}\text { Drafting/revision of the } \\
\text { manuscript for content, } \\
\text { including medical writing for } \\
\text { content; major role in the } \\
\text { acquisition of data; study } \\
\text { concept or design; analysis } \\
\text { or interpretation of data }\end{array}$ \\
\hline $\begin{array}{l}\text { Colleen } \\
\text { Maxwell, } \\
\text { PhD }\end{array}$ & $\begin{array}{l}\text { ICES, Toronto, Ontario, } \\
\text { Canada; Schools of } \\
\text { Pharmacy and Public Health } \\
\text { \& Health Systems, University } \\
\text { of Waterloo, Ontario, Canada }\end{array}$ & $\begin{array}{l}\text { Drafting/revision of the } \\
\text { manuscript for content, } \\
\text { including medical writing for } \\
\text { content; study concept or } \\
\text { design; analysis or } \\
\text { interpretation of data }\end{array}$ \\
\hline $\begin{array}{l}\text { Alyson } \\
\text { Mahar, PhD }\end{array}$ & $\begin{array}{l}\text { Department of Community } \\
\text { Health Sciences and } \\
\text { Manitoba Centre for Health } \\
\text { Policy, Max Rady College of } \\
\text { Medicine, Rady Faculty of } \\
\text { Health Sciences, University of } \\
\text { Manitoba, Winnipeg, } \\
\text { Canada; ICES Queen's, } \\
\text { Queen's University, Kingston, } \\
\text { Ontario, Canada }\end{array}$ & $\begin{array}{l}\text { Drafting/revision of the } \\
\text { manuscript for content, } \\
\text { including medical writing for } \\
\text { content; study concept or } \\
\text { design; analysis or } \\
\text { interpretation of data }\end{array}$ \\
\hline
\end{tabular}

\begin{tabular}{|c|c|c|}
\hline $\begin{array}{l}\text { Okechukwu } \\
\text { Ekuma, MSc }\end{array}$ & $\begin{array}{l}\text { Manitoba Centre for Health } \\
\text { Policy, Max Rady College of } \\
\text { Medicine, Rady Faculty of } \\
\text { Health Sciences, University of } \\
\text { Manitoba, Winnipeg, Canada }\end{array}$ & $\begin{array}{l}\text { Drafting/revision of the } \\
\text { manuscript for content, } \\
\text { including medical writing for } \\
\text { content; analysis or } \\
\text { interpretation of data }\end{array}$ \\
\hline $\begin{array}{l}\text { Chad } \\
\text { McClintock, } \\
\text { MSc }\end{array}$ & $\begin{array}{l}\text { ICES Queen's, Queen's } \\
\text { University, Kingston, Ontario, } \\
\text { Canada }\end{array}$ & $\begin{array}{l}\text { Drafting/revision of the } \\
\text { manuscript for content, } \\
\text { including medical writing for } \\
\text { content; analysis or } \\
\text { interpretation of data }\end{array}$ \\
\hline $\begin{array}{l}\text { Dallas Seitz, } \\
\text { MD, PhD }\end{array}$ & $\begin{array}{l}\text { ICES Queen's, Queen's } \\
\text { University, Kingston, Ontario, } \\
\text { Canada; Departments of } \\
\text { Psychiatry and Community } \\
\text { Health Sciences, Cumming } \\
\text { School of Medicine, } \\
\text { University of Calgary, } \\
\text { Alberta, Canada }\end{array}$ & $\begin{array}{l}\text { Drafting/revision of the } \\
\text { manuscript for content, } \\
\text { including medical writing for } \\
\text { content; study concept or } \\
\text { design; analysis or } \\
\text { interpretation of data }\end{array}$ \\
\hline $\begin{array}{l}\text { Patti } \\
\text { Groome, } \\
\text { PhD }\end{array}$ & $\begin{array}{l}\text { ICES Queen's and Division of } \\
\text { Cancer Care and } \\
\text { Epidemiology, Cancer } \\
\text { Research Institute, Queen's } \\
\text { University, Kingston, Ontario, } \\
\text { Canada }\end{array}$ & $\begin{array}{l}\text { Drafting/revision of the } \\
\text { manuscript for content, } \\
\text { including medical writing for } \\
\text { content; major role in the } \\
\text { acquisition of data; study } \\
\text { concept or design; analysis } \\
\text { or interpretation of data }\end{array}$ \\
\hline
\end{tabular}

\section{References}

1. Kingwell E, van der Kop M, Zhao Y, et al. Relative mortality and survival in multiple sclerosis: findings from British Columbia, Canada. J Neurol Neurosurg Psychiatry. 2012;83(1):61-66.

2. Marrie RA, Elliott L, Marriott J, et al. Effect of comorbidity on mortality in multiple sclerosis. Neurology. 2015;85(3):240-247.

3. Bronnum-Hansen H, Koch-Henriksen N, Stenager E. Trends in survival and cause of death in Danish patients with multiple sclerosis. Brain. 2004;127(pt 4): 844-850.

4. Cutter GR, Zimmerman J, Salter AR, et al. Causes of death among persons with multiple sclerosis. Mult Scler Relat Disord. 2015;4(5):484-490.

5. Marrie R, Reider N, Cohen J, et al. A systematic review of the incidence and prevalence of cancer in multiple sclerosis. Mult Scler. 2015;21(3):294-304.

6. Brenner DR, Weir HK, Demers AA, et al. Projected estimates of cancer in Canada in 2020. CMAJ. 2020;192(9):E199-E205.

7. Marrie RA, Maxwell C, Mahar A, et al. Breast cancer survival in multiple sclerosis: a matched cohort study. Neurology. 2021;97(1):e13-e22.

8. Roshanisefat H, Bahmanyar S, Hillert J, Olsson T, Montgomery S. All-cause mortality following a cancer diagnosis amongst multiple sclerosis patients: a Swedish population-based cohort study. Eur J Neurol. 2015;22(7):1074-1080. 
9. Mahar AL, Kurdyak P, Hanna TP, Coburn NG, Groome PA. The effect of a severe psychiatric illness on colorectal cancer treatment and survival: a population-based retrospective cohort study. PLoS One. 2020;15(7):e0235409.

10. Boakye D, Rillmann B, Walter V, Jansen L, Hoffmeister M, Brenner H. Impact of comorbidity and frailty on prognosis in colorectal cancer patients: a systematic review and meta-analysis. Cancer Treat Rev. 2018;64:30-39.

11. Chen V, Wu X, Andrews P. Cancer in North America, 1991-1995. Volume One: Incidence, 1st ed. Sacramento, CA: North American Association of Cancer Registries (NAACR); 1999.

12. Robles SC, Marrett LD, Aileen Clarke E, Risch HA. An application of capturerecapture methods to the estimation of completeness of cancer registration. J Clin Epidemiol. 1988;41(5):495-501.

13. Watson DE, Heppner P, Roos NP, Reid RJ, Katz A. Population-based use of mental health services and patterns of delivery among family physicians, 1992 to 2001. Can J Psychiatry. 2005;50(7):398-406.

14. Al-Sakran LH, Marrie RA, Blackburn DF, Knox KB, Evans CD. Establishing the incidence and prevalence of multiple sclerosis in Saskatchewan. Can J Neurol Sci. 2018;45(3):295-303.

15. Coleman MP, Forman D, Bryant H, et al. Cancer survival in Australia, Canada, Denmark, Norway, Sweden, and the UK, 1995-2007 (the International Cancer Benchmarking Partnership): an analysis of population-based cancer registry data. Lancet. 2011;377(9760):127-138.

16. Greene FL, Page DL, Fleming ID, et al. Ajcc Cancer Staging Manual, 6th ed. SpringerVerlag; 2002.

17. Brenner DR, Heer E, Sutherland RL, et al. National trends in colorectal cancer incidence among older and younger adults in Canada. JAMA Netw Open. 2019;2(7):e198090.

18. van Walraven $\mathrm{C}$, Austin PC, Jennings A, Quan $\mathrm{H}$, Forster AJ. A modification of the Elixhauser comorbidity measures into a point system for hospital death using administrative data. Med Care. 2009;47(6):626-633.

19. Turcotte LA, Marrie RA, Patten SB, Hirdes JP. Clinical profile of persons with multiple sclerosis across the continuum of care. Can J Neurol Sci. 2018;45(2):188-198.

20. Huyer G, Brown CRL, Spruin S, et al. Five-year risk of admission to long-term care home and death for older adults given a new diagnosis of dementia: a populationbased retrospective cohort study. CMAJ 2020;192(40):E422-E430.

21. Mojaverian N, Ng R, Hsu A. Validation of Incident Long-Term Care Admissions in Ontario Using Administrative Data.Toronto: ICES; 1998.

22. $\mathrm{Ng} \mathrm{R}$, Lane $\mathrm{N}$, Tanuseputro $\mathrm{P}$, et al. Increasing complexity of new nursing home residents in Ontario, Canada: a serial cross-sectional study. J Am Geriatr Soc. 2020; 68(6):1293-1300.

23. Brydges CR. Effect size guidelines, sample size calculations, and statistical power in gerontology. Innov Aging. 2019;3(4):igz036.

24. Mansournia MA, Hernán MA, Greenland S. Matched designs and causal diagrams. Int J Epidemiol. 2013;42(3):860-869.

25. Hahn EE, Gould MK, Munoz-Plaza CE, Lee JS, Parry C, Shen E. Understanding comorbidity profiles and their effect on treatment and survival in patients with colorectal cancer. J Natl Compr Canc Netw. 2018;16(1):23-34.

26. Kingwell E, Bajdik C, Phillips N, et al. Cancer risk in multiple sclerosis: findings from British Columbia, Canada. Brain. 2012;135(pt 10):2973-2979.

27. Collett D. Modelling Survival Data in Medical Research, 2nd ed. Chapman \& Hall/ CRC; 2003.

28. Varadhan R, Weiss CO, Segal JB, Wu AW, Scharfstein D, Boyd C. Evaluating health outcomes in the presence of competing risks: a review of statistical methods and clinical applications. Med Care. 2010;48(2 suppl):S96-S105.

29. Hertzmark E, Spiegelman D. SAS METAANAL Macro. 2012.
30. Higgins JPT, Thompson SG, Deeks JJ, Altman DG. Measuring inconsistency in metaanalyses. BMJ. 2003;327(7414):557-560.

31. Localio A, Stack CB, Griswold ME. Sensitivity analysis for unmeasured confounding. E-Values Observational Stud. 2017;167(1):285-286.

32. VanderWeele TJ, Ding P. Sensitivity analysis in observational research: introducing the E-value. Ann Intern Med. 2017;167(4):268-274

33. Gross CP, McAvay GJ, Krumholz HM, Paltiel A, Bhasin D, Tinetti ME. The effect of age and chronic illness on life expectancy after a diagnosis of colorectal cancer: implications for screening. Ann Intern Med. 2006;145(9):646-653.

34. Mariotto AB, Wang Z, Klabunde CN, Cho H, Das B, Feuer EJ. Life tables adjusted for comorbidity more accurately estimate noncancer survival for recently diagnosed cancer patients. J Clin Epidemiol. 2013;66(12):1376-1385.

35. Dabbikeh A, Peng Y, Mackillop WJ, Booth CM, Zhang-Salomons J. Temporal trends in the association between socioeconomic status and cancer survival in Ontario. a population-based retrospective study. CMAJ Open. 2017;5(3):E682-E689.

36. Quipourt V, Jooste V, Cottet V, Faivre J, Bouvier A-M. Comorbidities alone do not explain the undertreatment of colorectal cancer in older adults: a French populationbased study. J Am Geriatr Soc. 2011;59(4):694-698.

37. Chagpar R, Xing Y, Chiang YJ, et al. Adherence to stage-specific treatment guidelines for patients with colon cancer. J Clin Oncol. 2012;30(9):972-979.

38. Garland A, Metz LM, Bernstein CN, Peschken CA, Hitchon CA, Marrie RA. Hospitalization is associated with subsequent disability in multiple sclerosis. Mult Scler Relat Disord. 2017;14:23-28.

39. Marrie RA, Tremlett H, Kingwell E, et al. Disparities in management and outcomes of myocardial infarction in multiple sclerosis: a matched cohort study. Mult Scler. 2020 26(12):1560-1568

40. Marrie RA, Bernstein CN, Peschken CA, et al. Intensive care unit admission in multiple sclerosis: increased incidence and increased mortality. Neurology. 2014, 82(23):2112-2119.

41. Handforth C, Clegg A, Young C, et al. The prevalence and outcomes of frailty in older cancer patients: a systematic review. Ann Oncol. 2015;26(6):1091-1101.

42. Ayrignac X, Larochelle C, Keezer M, et al. Frailty in ageing persons with multiple sclerosis. Mult Scler. 2021;27(4):613-620.

43. Trogdon JG, Chang Y, Shai S, et al. Care coordination and multispecialty teams in the care of colorectal cancer patients. Med Care. 2018;56(5):430-435.

44. Makhoul R, Alva S, Wilkins KB. Surveillance and survivorship after treatment for colon cancer. Clin Colon Rectal Surg. 2015;28(4):262-270.

45. Lund JL, Harlan LC, Yabroff KR, Warren JL. Should cause of death from the death certificate be used to examine cancer-specific survival? A study of patients with distant stage disease. Cancer Invest. 2010;28(7):758-764.

46. Percy C, Stanek E III, Gloeckler L. Accuracy of cancer death certificates and its effect on cancer mortality statistics. Am J Public Health. 1981;71(3):242-250.

47. Withrow DR, Pole JD, Nishri ED, Tjepkema M, Marrett LD. Choice of relative or cause-specific approach to cancer survival analysis impacts estimates differentially by cancer type, population, and application: evidence from a Canadian population-based cohort study. Popul Health Metr. 2017;15(1):24

48. Eaglehouse YL, Georg MW, Shriver CD, Zhu K. Racial differences in time to breast cancer surgery and overall survival in the US military health system. JAMA Surg. 2019; 154(3):e185113

49. Ordóñez-Mena JM, Walter V, Schöttker B, et al. Impact of prediagnostic smoking and smoking cessation on colorectal cancer prognosis: a meta-analysis of individual patient data from cohorts within the chances consortium. Ann Oncol. 2018;29(2):472-483.

50. Amin M, ed. AJCC Cancer Staging Manual, 8th ed. Springer International Publishing; 2018 . 


\section{Neurology}

Colorectal Cancer Survival in Multiple Sclerosis: A Matched Cohort Study

Ruth Ann Marrie, Colleen Maxwell, Alyson Mahar, et al.

Neurology 2021;97;e1447-e1456 Published Online before print September 15, 2021

DOI 10.1212/WNL.0000000000012634

This information is current as of September 15, 2021

\section{Updated Information \&} Services

References

Citations

Subspecialty Collections

Permissions \& Licensing

Reprints including high resolution figures, can be found at: http://n.neurology.org/content/97/14/e1447.full

This article cites 44 articles, 10 of which you can access for free at: http://n.neurology.org/content/97/14/e1447.full\#ref-list-1

This article has been cited by 1 HighWire-hosted articles: http://n.neurology.org/content/97/14/e1447.full\#\#otherarticles

This article, along with others on similar topics, appears in the following collection(s):

All Health Services Research

http://n.neurology.org/cgi/collection/all_health_services_research Cohort studies

http://n.neurology.org/cgi/collection/cohort_studies

Multiple sclerosis

http://n.neurology.org/cgi/collection/multiple_sclerosis

Information about reproducing this article in parts (figures,tables) or in its entirety can be found online at:

http://www.neurology.org/about/about_the_journal\#permissions

Information about ordering reprints can be found online:

http://n.neurology.org/subscribers/advertise

Neurology ${ }^{\circledR}$ is the official journal of the American Academy of Neurology. Published continuously since 1951, it is now a weekly with 48 issues per year. Copyright Copyright (C) 2021 The Author(s). Published by Wolters Kluwer Health, Inc. on behalf of the American Academy of Neurology.. All rights reserved. Print ISSN: 0028-3878. Online ISSN: 1526-632X.

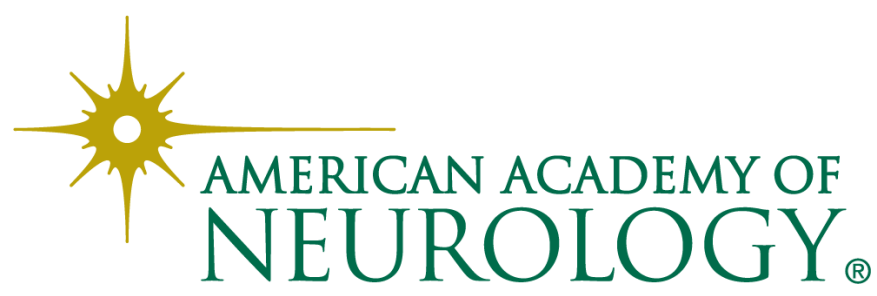

